\title{
Análise de publicidade da revista Veja
}

\author{
$\mathrm{N}$ ilton $\mathrm{H}$ ernandes \\ Universidade de São Paulo, São Paulo, Brasil \\ http:/ / sites.uol.com.br/ niltonhernandes \\ nh38@uol.com.br
}

\begin{abstract}
This study aims to analyse one important publicity about VEJA magazine e the mechanisms of production of meaning. We are interested about the values associated with the brand. The ad has three pages and was published in the magazine $30^{\text {th }}$ anniversary edition. O ne of its main subject is the unemployment.
\end{abstract}

Resumo: O presente estudo se concentra em uma importante publicidade da revista VEJA para verificar que sentidos são manejados e acrescentados à marca. $\mathrm{O}$ anúncio tem três páginas e foi publicado na edição de aniversário de 30 anos da revista. Um dos principais temas abordados é o do desemprego.

\section{Introdução}

VEJA é a revista mais comprada no País e uma das mais lidas no mundo. Desde 1995, são impressos mais de um milhão de exemplares toda semana. ${ }^{1} \mathrm{VEJA}$, Isto É, Época, ou mesmo o Jornal Nacional, ou a Folha de São Paulo são exemplos de marcas de veículos jornalísticos, cada qual com um “corpo" e uma "personalidade”, um tom de voz. A identidade que carregam é atualizada de duas maneiras diferentes e complementares: a cada edição e em publicidades. 0 objetivo deste estudo é analisar os sentidos manejados pela publicidade. ${ }^{2}$

\footnotetext{
1 A informação aparece na seção Ponto de Vista, assinada por Roberto Civita, p. 146, na edição especial de 30 anos, parte da VEJA 1569, de outubro de 1998.

${ }^{2}$ Este trabalho é parte da dissertação de mestrado "A revista Veja e o discurso do emprego na globalização -
} http:/ / www.fclar.unesp.br/ pesq/ grupos/ CASA-home.html 25 
A construção da identidade da VEJA teve em 1998 um momento especial. A revista comemorou 30 anos no mercado e aproveitou a oportunidade para iniciar uma grande ofensiva publicitária. Uma das principais ações de reforço da marca foi a entrega de uma edição comemorativa junto com a semanal, número 1569, de 21 de outubro, que transforma a principal publicação da Editora Abril em notícia. Na revista de aniversário, de 148 páginas, há uma publicidade da própria VEJA, com três páginas (126 a 128), criada pela ALMAP/ BBD O, que é nosso objeto de estudo. 0 primeiro contato do leitor é com as duas páginas centrais:

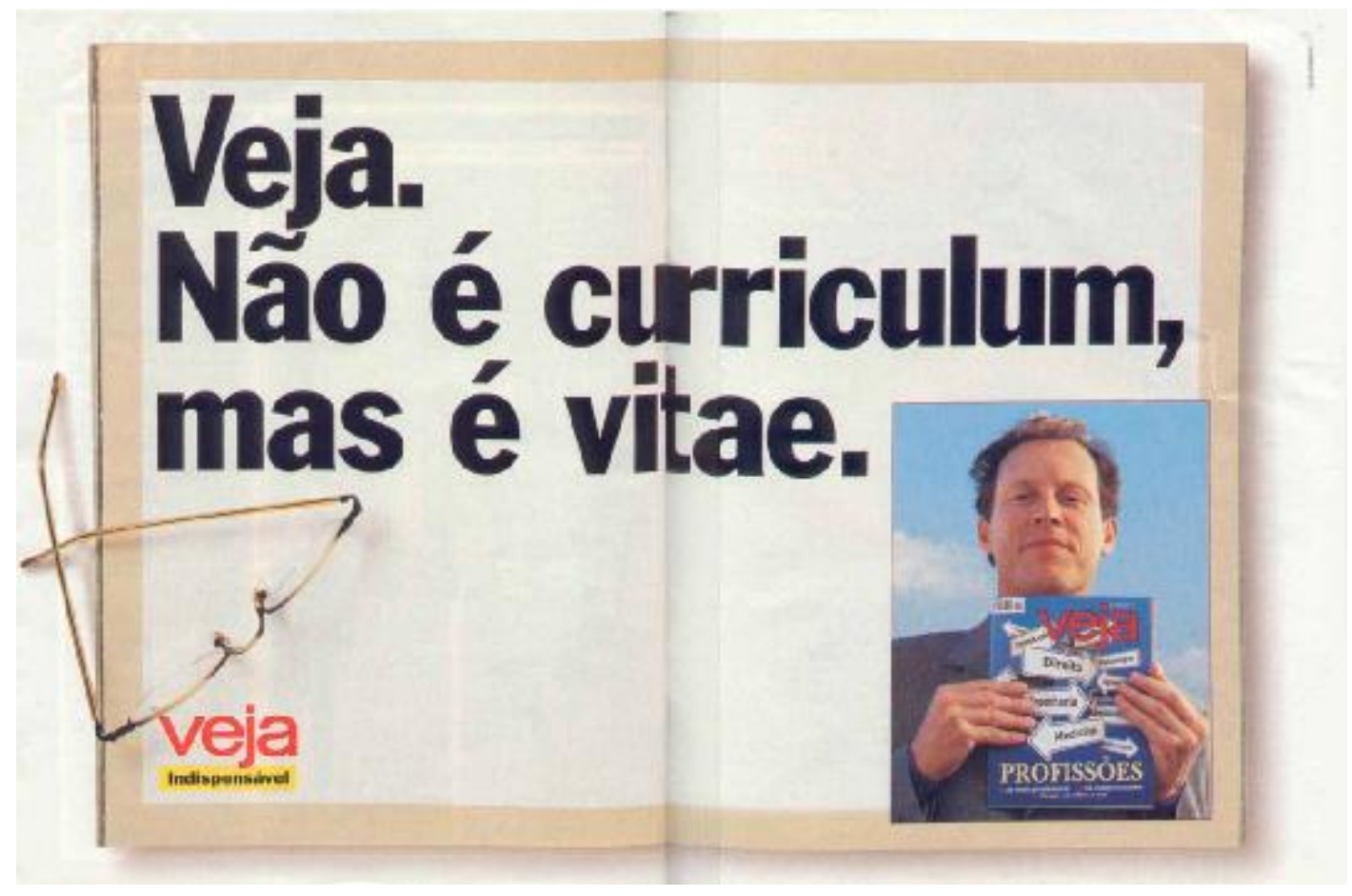

Uma análise semiótica", FFLCH/USP, 2001. A dissertação mostra como a revista VEJA tratou da questão do emprego em momento crítico da globalização. Buscou-se analisar como os textos da publicação são construídos, como conseguem transformar recortes e interpretações de acontecimentos em "fatos", em verdades aceitas que, juntas, formam um simulacro sedutor da realidade que impele os leitores a determinadas crenças e ações. O corpus principal é formado por cinco números da VEJA, selecionados de um total de 93 edições, veiculadas entre 4 de dezembro de 1996 e 27 de janeiro de 1999. As edições escolhidas abordam o tema do emprego por meio de manchete de primeira página, ou seja, com máximo destaque editorial. Também foi analisada a publicidade da própria VEJA - que apresentamos aqui - para verificar os valores associados à marca e de que modo influencia os outros textos da revista. A dissertação pode ser acessada no site: http://sites.uol.com.br/niltonhernandes 
Ao virar página, há a segunda parte do anúncio:

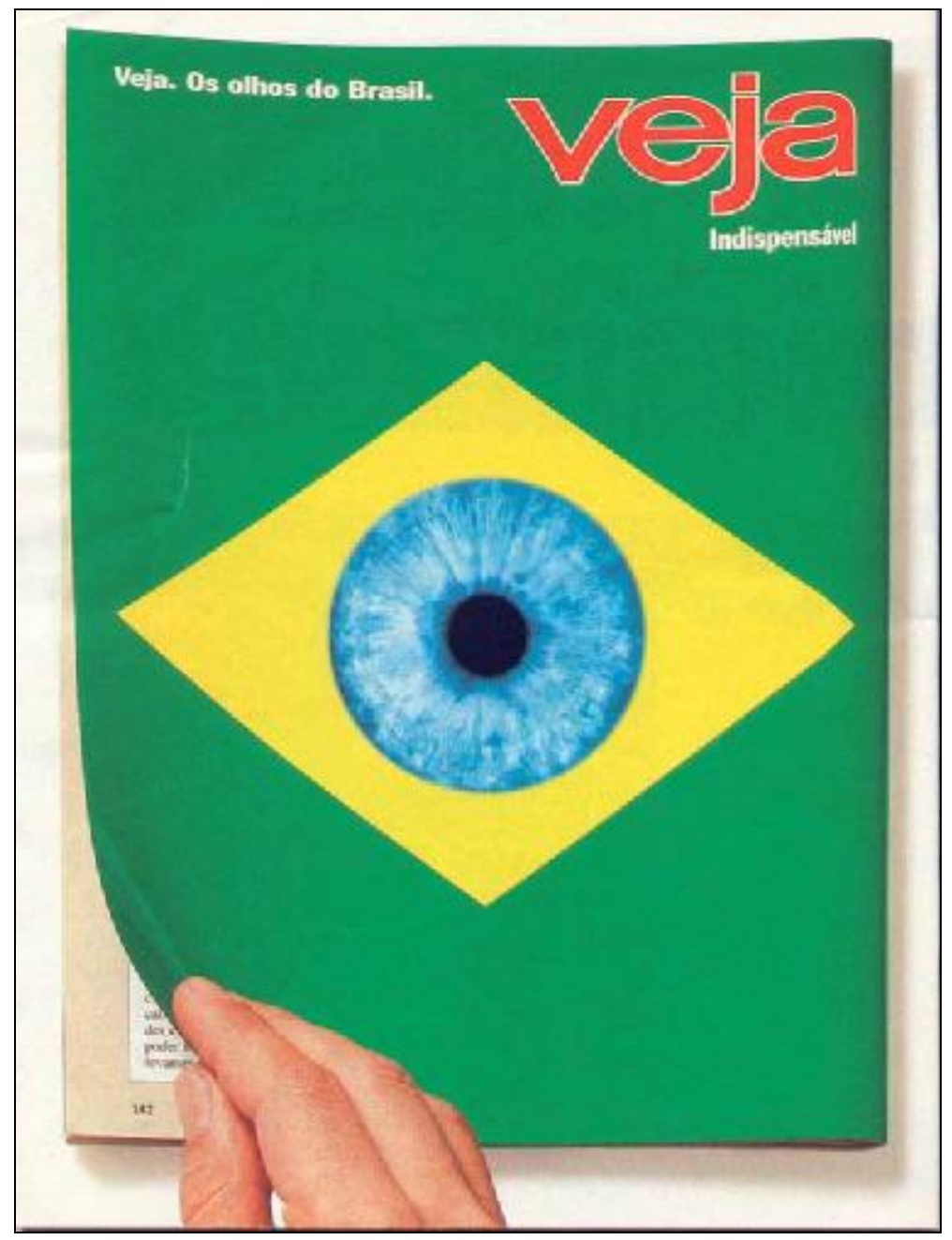

A edição comemorativa, como um todo, já é publicidade da própria VEJA, embora mantenha 0 tom jornalístico, hierarquizando, apresentando e interpretando "fatos". A grande diferença, obviamente, é o recorte temporal. Não se fala, como de costume, do que ocorreu de mais importante - na ótica da revista - no intervalo de sete dias, mas no período de 30 anos de vida da publicação. Ao relembrar, como afirma na pág. 12, "grandes momentos", como a chegada do homem na lua, a queda do muro de Berlim e a revolução tecnológica, VEJA reforça e valoriza a própria imagem, seu papel de testemunha, mediadora, organizadora e intérprete da história que apresenta ao seu público. Na Carta ao leitor, página 6, lê-se: “0 que está publicado é apenas o suficiente para contar o que as reportagens continham de mais significativo. (...). 0 
resultado é um conjunto de leitura dinâmica e agradável, que não apenas narra histórias importantes. 0 material mostra também a interpretação e as conclusões que VEJA tirou a partir delas". A revista coloca sua função jornalística no mesmo nível de importância dos fatos mostrados. É um auto-elogio, uma afirmação com objetivo de reforçar os laços existentes entre VEJA e seu público. 0 anúncio estudado a seguir se insere, portanto, em uma revista que já é publicidade implícita e completa o reforço da marca.

Durante todo o ano de 1998, em diversas edições de VEJA, anúncios semelhantes foram publicados e se somaram a outras estratégias, como a veiculação em outdoor, semanalmente, das capas seguidas de comentários curtos e com certo humor. Publicidades da VEJA também apareceram em outras revistas do grupo Abril Cultural, jornais de circulação nacional, cartazes em bancas, letreiros. Acreditamos, porém, que a criação e a veiculação do anúncio estudado obedeceu a critérios mais cuidadosos justamente por fazer parte de uma edição comemorativa. Foram escolhidas não apenas as notícias de maior destaque reportadas por VEJA, como também o tipo de publicidade que pudesse ser mais efetiva e significativa no contexto do aniversário. Julgamos, portanto, que o anúncio estudado, pela inserção na edição especial, é um dos mais representativos da campanha que atravessou ainda os últimos anos e dá uma boa idéia dos conceitos relacionados à marca.

Um fato importante é que, ainda em 1998, precisamente em 25 de maio, começou a circular o primeiro número da revista Época, semanário de notícias da maior empresa de comunicação do País, a Rede Globo, e concorrente direta de VEJA. É poca foi baseada na revista Focus, da Alemanha, notadamente na busca de maior sofisticação visual, com grande uso de recursos de computação gráfica. Estamos associando - intertextualmente - 0 anúncio de VEJA dentro do contexto de aparecimento da revista Época.

\section{Plano de conteúdo - nível narrativo}

Iniciamos o estudo do plano de conteúdo pelo nível intermediário, o narrativo. Analisar o nível narrativo do anúncio é descrever a história contada, determinar seus participantes e 0 papel que representam. "As estruturas narrativas simulam tanto a história do homem em busca de valores ou à procura de sentido quanto a dos contratos e dos conflitos que marcam os relacionamentos humanos" (BARROS, 1997, pág. 16). 
Existem três performances no anúncio, todas marcadas visualmente. A primeira, e mais intrigante, é a de um leitor que "folheia" uma representação da própria VEJA após deixar seus óculos sobre uma das páginas. No final da publicidade, ele aparece fechando a revista. Há a simulação de um percurso de leitura que está chegando ao fim. Esse sujeito será chamado de leitor de óculos. Na última página, um estranho "olho", mesclado a uma bandeira brasileira, fita 0 leitor de óculos que fecha a "revista". Trata-se da segunda performance. Está acontecendo uma ação de olhar, vigiar. E o olhar é da publicação, como reforça a frase no canto esquerdo: "VEJA. Os olhos do Brasil." Enquanto o leitor de óculos relaxa ao concluir sua leitura, a revista se faz atenta, tensa.

Retornemos à foto da segunda página. Há um rapaz de terno que segura a VEJA. Vamos chamá-lo de leitor jovem. Existem duas interpretações possíveis da imagem. Numa primeira leitura, surge a terceira performance. Há um sujeito realizado, ou seja, que concluiu uma ação bem sucedida. VEJA é apresentada pelo sujeito como parte integrante do sucesso da performance. Essa é a interpretação mais provável. A VEJA que ele segura é a 1509, do ano anterior, de 20 de agosto de 1997. No período de um ano, ele se preparou e encontrou o emprego graças às dicas da publicação. A data, no entanto, não é perceptível no anúncio. A interpretação, para ganhar força, exige um leitor com acesso a um conjunto maior de revistas. Na segunda possibilidade de leitura, o jovem executivo pode ser interpretado como um sujeito ainda em busca de seu objeto "emprego", portanto, ainda sem realizar a ação. ${ }^{3}$

\footnotetext{
${ }^{3}$ Em semiótica, existe sentido se um sujeito parte em busca de um objeto. Sentido, portanto, aparece aqui na acepção de "direção". Essa leitura também esclarece que o sentido nasce da quebra de uma situação de harmonia e da necessidade de sua retomada. A performance, ou ação, é justamente essa busca do sujeito para encontrar seu objeto e obter determinados valores. Podemos pensar em um sujeito que quer encontrar trabalho (o objeto) para ter acesso a uma forma de respeito social (valor do objeto).Todas as ações do sujeito podem ser resumidas num único verbo: fazer. A semiótica de Greimas entende a ação (o fazer) do sujeito como diferentes combinações de apenas quatro verbos, chamados modais: querer, dever, poder e saber. Quem maneja as crenças (ou o crer) do sujeito é o destinador, fonte de valores do sujeito. É ele que manipula o sujeito (aqui no papel de destinatário) para a ação. A semiótica verificou a existência de quatro grandes tipos de manipulação do destinador, aqui exemplificadas na relação mãe e filho: 1 - Tentação: "Se você comer a carne, ganha o doce."

2 - Intimidação: "Se você não comer, não vai ganhar doce nunca mais."

3 - Sedução: "Só uma criança bonita como você é capaz de comer tudo."

4 - Provocação: "O seu prato está cheio, mas como eu sei que você ainda é pequeno, não consegue comer tudo."
} 
Em semiótica, a performance de um sujeito em busca de um objeto pressupõe a aquisição de competência para realizar a ação. Também por pressuposição, é possível afirmar que há um destinador do jovem executivo: a sociedade, fonte de valores que o sujeito assume. É a sociedade que o fez querer realizar a performance de busca do melhor emprego (ou até mesmo de um emprego) manipulando-o por tentação. Ele quer, com o objeto, ter acesso aos valores de sucesso profissional, material e, em última instância, ao prestígio social, sanção positiva da própria sociedade que o transformou num sujeito desejante. Mas não basta apenas querer: É preciso ainda, saber e poder realizar a performance. Nesse ponto entra VEJA. A revista doa as competências necessárias para o executivo, tanto na primeira como na segunda leitura da foto.

Os outros elementos verbais do anúncio explicitam melhor esta competência. Temos a frase em negrito "Veja. Não é curriculum, mas é vitae." e o slogan "indispensável" (que aparece duas vezes, na primeira e terceira páginas). Se a foto comunica que a revista se liga a uma perfórmance, a frase e o slogan complementam que, sem ter VEJA como doadora da competência, não se encontra o desejado emprego. Não há alternativas, não existem outros caminhos. 0 saber e 0 poder doados por VEJA são imprescindíveis e insubstituíveis para 0 sujeito realizar a ação. Conclui-se que as informações transmitidas pela publicação se mostram narrativamente no mesmo nível dos objetos mágicos dos contos de fada, como a espada que dá poderes especiais ao príncipe e lhe permite vencer os inimigos, conquistar a princesa e 0 reino. Mais adiante, no nível discursivo, será retomada a análise do slogan.

\section{Nível fundamental}

Nos três percursos narrativos - 0 do jovem executivo na primeira leitura, o da VEJA e 0 do leitor de óculos que vira as páginas -, há, no nível fundamentall, oposições semânticas entre vida x morte, na categoria existencial, tensão x relaxamento, na categoria temporal. Tanto a vida quanto a tensão são mostradas no texto como ligadas a valores positivos.

No percurso do jovem executivo, que apresenta a oposição semântica vida x morte, 0 texto vai concretizar depois a idéia de vida na forma do trabalhador que tem um bom emprego.

\footnotetext{
${ }^{4} \mathrm{O}$ nível fundamental abriga as oposições básicas de construção de um texto. É a partir dessa relação que se inicia o chamado percurso gerativo de sentido, um caminho de enriquecimentos semânticos. Não começamos a análise pelo nível fundamental só para mostrar que é mais fácil buscar a oposição de base do texto após o exame do nível narrativo.
} 
O que pressupõe que o desemprego, por sua vez, está relacionado com a morte. Também por pressuposição, é possível verificar que houve mudanças de estados, uma passagem da morte (situação de desemprego) para a não-morte (busca do emprego), e finalmente para a vida (encontro do emprego) na primeira leitura da foto. $\mathrm{Ou}$ um percurso ainda em andamento na segunda leitura, que sai da morte (situação de desemprego) para a não-morte (busca do emprego).

\section{Nível discursivo}

A análise discursiva semiótica opera sobre os mesmos elementos da narrativa, porém retoma aspectos deixados de lado, como os recursos de persuasão utilizados, dessa vez para manipular o leitor final, entre outros. Para exame do discurso, pode-se pensar em algumas questões iniciais: qual é a função, na estratégia de persuasão discursiva, dos três percursos já descritos no nível narrativo: 0 jovem executivo na foto, o leitor de óculos que vira as páginas e fecha uma VEJA e o olho-bandeira que se mantém atento?

A primeira característica do anúncio é ser um metadiscurso, ou seja, VEJA fala de si própria, e em três níveis diferentes. É mostrada nas mãos do jovem executivo, ou do leitor jovem. Em seguida, aparece nas duas páginas iniciais, em escala apenas 10\% menor, sendo manuseada pelo leitor de óculos, e, finalmente, nas mãos do leitor enunciatário ou leitor final, como edição de aniversário. Tudo isso sem contar os outros efeitos de sentido contextuais, provocados pela inserção da publicidade numa edição comemorativa de 30 anos que fala 0 tempo todo das ações da própria revista.

O leitor de óculos faz a passagem entre as duas partes distintas do anúncio, a que se relaciona com 0 emprego e a que mostra a vigilância sobre o Brasil. Em ambas, VEJA se apresenta no logotipo e se diz "indispensável" no slogan. O reforço é pouco comum na publicidade.

Analisemos a primeira parte. Do ponto de vista das estratégias discursivas, o jovem executivo que aparece na foto é um argumento de ilustração. 0 rapaz olha e se comunica com 0 leitor. Também segura uma edição que se apresenta como um guia prático para a busca de uma boa colocação profissional. Na primeira leitura possível, como já foi analisado, pode-se interpretar a expressão de satisfação contida como a realização de uma performance bem sucedida de obtenção de um bom emprego. 0 terno mostra que se trata de um trabalhador de 
elite, o que comanda, o que ganha o melhor salário, no topo da pirâmide social, o "vencedor". Ele aparece num ambiente aberto, iluminado pela luz do sol. Não está fechado em algum lugar, preso. Tem horizontes, pode ir onde quiser. A performance realizada foi, portanto, a mais difícil, a mais cheia de obstáculos e de maior recompensa. 0 jovem aparece como alguém que aceitou a persuasão realizada pela revista, a considerou realmente "indispensável", e se deu bem, encontrou um bom emprego. VEJA, para provar uma verdade geral, apresenta um caso particular. Tenta-se persuadir o enunciatário por tentação: se ele acreditar em VEJA, como 0 jovem executivo, também pode obter sucesso profissional. Mesmo na segunda leitura, da performance ainda não realizada, a mesma manipulação acontece: se o jovem executivo confiou, por que o leitor não pode também acreditar na competência da revista em ser fonte de saber e poder?

O rapaz também tem outras funções no anúncio. Trabalha-se, com a foto dele, com um efeito de realidade, de não apenas argumentar verbalmente, mas mostrar alguém de "carne e osso". Parece que um narrador (o que afirma "VEJA"), instalado no texto, cedeu a palavra para que 0 jovem se manifestasse. Ele "diz", porém, com gestos. Mostra a revista, sua contida satisfação e um certo equilíbrio, de quem sabe onde quer chegar.

Ao olhar para o leitor-final, o jovem executivo mostra o investimento do anúncio no tom de proximidade. Temos uma relação eu-tu. Não se fala para milhões de pessoas, mas para uma em especial. 0 processo de massificação, inerente à publicidade, é apagado. Existem, no entanto, sutilezas, marcadas a partir da relação da foto com a parte verbal. Na frase principal - "Veja. Não é curriculum, mas é vitae.", a primeira palavra pode ser entendida como o nome da revista. Mas é também uma ordem, um imperativo, um "perceba", "fique atento". Há, no efeito de ambigüidade de sentidos, a apresentação de um fato sobre a revista e também um chamamento do leitor para perto. (Na segunda parte do anúncio, o mesmo recurso é utilizado na frase "VEJA. Os olhos do Brasil.". $)^{5}$

Curriculum vitae é uma expressão do latim que quer dizer carreira da vida. 0 dicionário Aurélio a coloca como sinônima de currículo, e a define como "conjunto de dados concernentes ao estado civil, ao preparo profissional e às atividades anteriores de quem se candidata a um emprego". A frase joga com a expressão curriculum vitae negando os termos para criar um

\footnotetext{
${ }^{5}$ A Semiótica chama este efeito de proximidade de desembreagem enunciativa.
} 
paradoxo, um efeito de estranhamento que gera surpresa e, dessa maneira, agrega novas significações à palavra vitae. Afirma-se que a revista não é "curriculum", ou seja, não é parte da carreira, mas somente para dizer com mais ênfase que é vital ("indispensável") na busca de uma boa posição profissional. Também permite a leitura de que 0 valor relacionado ao trabalho, do qual VEJA é parte integrante como doadora de competência para realizar a ação, é a vida, a própria existência. A frase, para concluir, maneja uma ambigüidade lexical (caso do jogo com a palavra VEJA), e de estrutura (ao fazer uma negação de termos de uma expressão em latim, dá novos sentidos à Vitae).

\section{0 slogan "Indispensável"}

Na primeira parte do anúncio, a frase principal e a foto se relacionam também com 0 slogan "indispensável" e o logotipo de VEJA. Antes de iniciar o exame das relações, é conveniente fazer um pequeno histórico do slogan. Ele surge pela primeira vez na edição 1531, de 28 de janeiro de 1998, oito meses antes do aniversário de 30 anos, comemorado em setembro. A palavra "indispensável" é parte de um selo comemorativo.

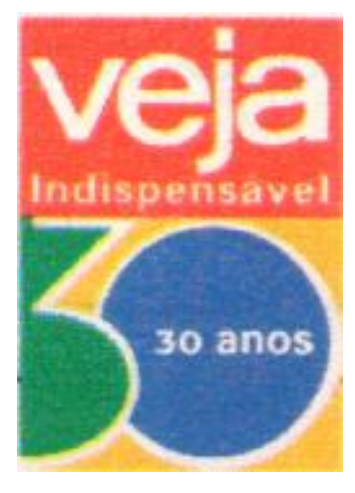

O slogan começou então a aparecer na revista também ligado ao logotipo, com grande variação de cores, dentro ou não de um retângulo, como mostrado a seguir:

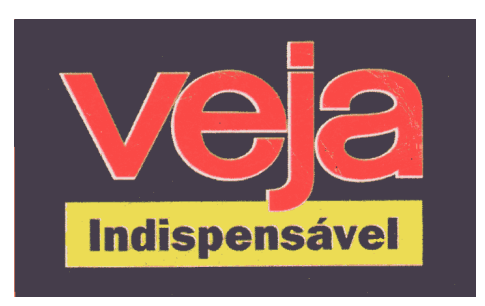


É notável ainda o quanto a frase lembra outro slogan mais antigo, o da Folha de São Paulo. Ambos têm sentidos e são visualmente muito parecidos. 0 mostrado em seguida foi retirado da própria VEJA, em um anúncio da Videoteca Folha, de 11 de junho de 1997 (edição 1499 - p. 132/ 133).

\section{FOLHA Nabodapranated}

O slogan pretende manipular o leitor habitual por intimidação implícita: os sentidos do "indispensável" (semioticamente, temos um não-poder-não-ser) se vinculam a ações obrigatórias do dia-a-dia, ao dever-ser, ou a uma rotina na qual existem deveres. A revista se coloca como "imprescindível", "que não se pode dispensar", "que é absolutamente necessária", "essencial", acrescenta o dicionário Aurélio. A leitura aparece como parte das atividades vitais. Dispensar a revista vincula-se a um grave prejuízo pessoal. VEJA, portanto, tenta persuadir seu leitor de que não há como se safar: a revista é obrigatória.

0 "indispensável" também manipula por provocação. Pode-se imaginar que o slogan comunica ainda a um provável leitor: "Só quem não quer ter acesso a possibilidades profissionais interessantes não lê a VEJA."

De qualquer maneira, o "indispensável" tem uma carga negativa e se apresenta como uma conclusão ligada à revista que deixa, para a interpretação do leitor, as premissas que lhe atribuem sentido mais preciso. Para decifrar o slogan, é preciso buscar informações no texto no qual se insere. Na primeira parte do anúncio, as premissas citadas se vinculam ao tema do trabalho. Por que VEJA é "indispensável"? D evido ao fato de ser decisiva, "vitae", para encontro de emprego e de conseqüente sucesso profissional.

Se a foto trabalha com uma manipulação por tentação, com a idéia de prêmio na forma de sucesso profissional, o slogan, por sua vez, acrescenta que há também um castigo em não ler a revista e se negar a acreditar nos valores a ela associados. Q uem não comprar a VEJA não irá se transformar num executivo de sucesso, não encontrará um bom emprego e nem terá direito a 
uma existência digna de ser vivida. Tenta-se fazer crer no valor da revista por meio de recompensas, mas sutilmente também pelo medo.

\section{Outros percursos e argumentos}

Vamos agora analisar os outros dois percursos do anúncio e a relação com o primeiro. Na página inicial, há uns óculos dobrados no canto esquerdo. Sugere-se assim que o leitor de óculos está descansando os olhos. Na página seguinte, segunda parte do anúncio, notam-se dedos simulando o fechamento da revista e remetendo à idéia de conclusão de leitura. Há duas metonímias, mais precisamente sinédoques, uma visual (os óculos) e outra tátil: as partes (como os óculos e os dedos) representam um todo, o leitor de óculos. Ao mesmo tempo, o olhobandeira fita 0 leitor (aqui tanto o leitor de óculos como o leitor final). Temos outras duas metonímias visuais que se fundem na imagem-fusão ${ }^{6}$. Trabalha-se com uma idéia de relação por implicação. A bandeira estilizada representa o Brasil. A íris azul, conjugada à bandeira, remete a um ato contínuo de vigilância sobre o espaço brasileiro. A frase "VEJA. Os olhos do Brasil." reafirma as duas interpretações. Brasil, nesse caso, pode ser entendido como a nação, como a sociedade brasileira. A revista pratica aqui também uma das missões do jornalismo que é a de vigiar, estar atenta e reportar acontecimentos, contradições, falcatruas. A publicação é mostrada como participante dos destinos brasileiros, daí a idéia de fusão entre 0 ato de olhar (que caracteriza uma representação do próprio nome da publicação) com a bandeira brasileira. A idéia de porta-voz aqui foi substituída pela de "porta-olhos". Reitera-se o sentido da visão que remete novamente ao nome da revista. $\mathrm{O}$ anúncio, como um todo, é marcado pela isotopia (reiteração semântica) do olhar: temos as frases que falam "Veja...", o nome da revista, os óculos, o olhobandeira.

A união dos dois percursos (a do leitor de óculos e o da vigilância exercida por VEJA) forma um outro argumento de ilustração. A imagem do leitor de óculos simula a do leitor final. Pretende mostrar que ele, assim como o leitor dono dos óculos, também pode descansar depois

\footnotetext{
${ }^{6}$ Os profissionais de VEJA chamam de fusão a união de diferentes imagens de diversas origens (desenhos, fotos, letras, etc.) para construir um único objeto visual. Por questões de clareza, vamos chamar esse tipo de elemento - que aparece em diversos textos analisados neste trabalho - de imagem-fusão
} 
da leitura da edição. No fechar da página 142 (canto esquerdo inferior) podem ser lidas as palavras "poder" e "levante":

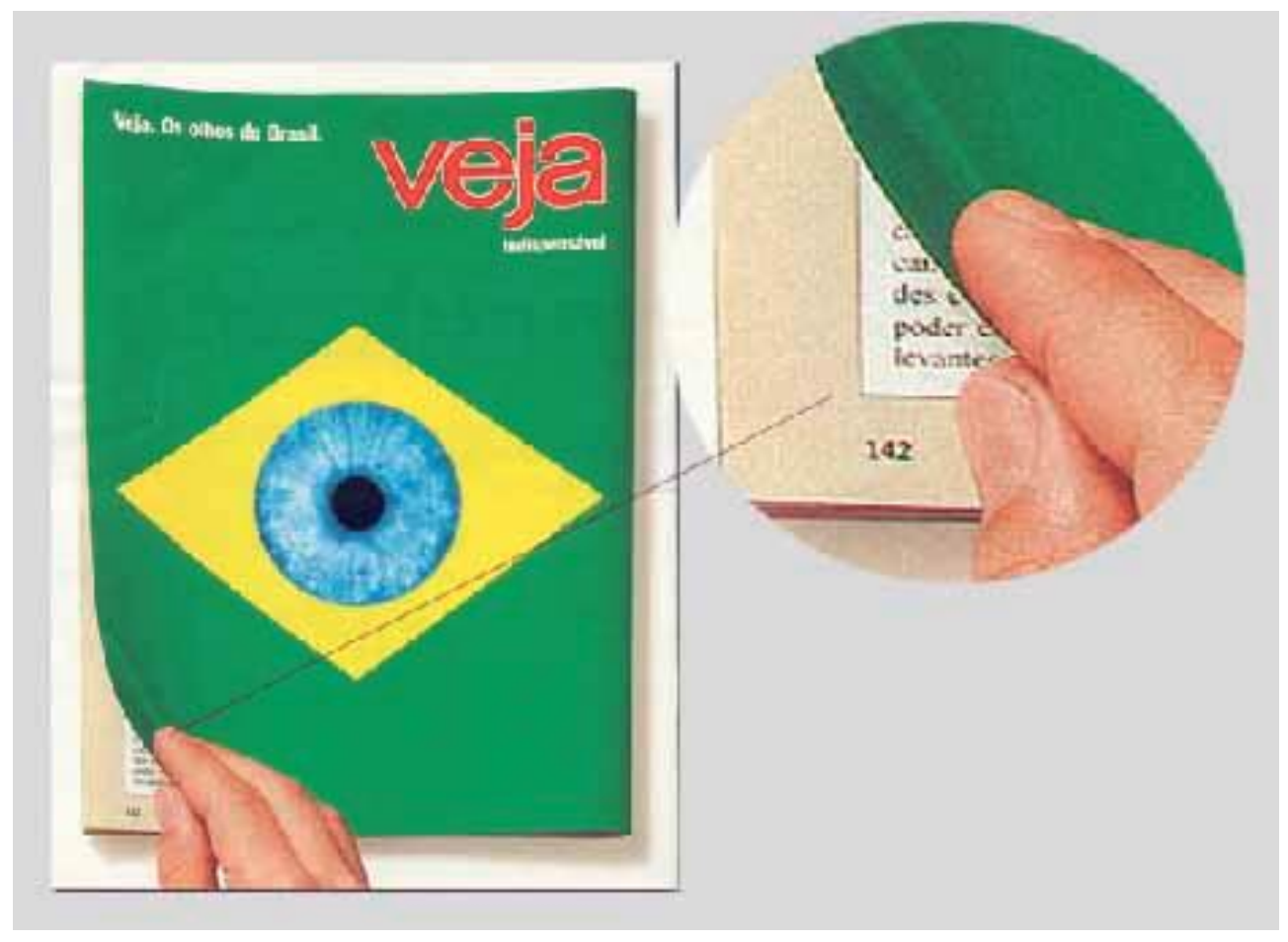

Simula-se um fragmento de comentário ou notícia de uma sociedade retratada em grande transformação, que exige atenção contínua do leitor. Mas ele somente pode relaxar porque VEJA está fazendo seu trabalho (e a dubiedade do pronome possessivo aqui é pertinente: trata-se do trabalho do leitor e da própria revista). VEJA está patrulhando o Brasil, fazendo denúncias, selecionando e divulgando as notícias que o permitirão se posicionar diante da realidade brasileira. 0 "indispensável" adquire, nesse segundo contexto, o fluxo contínuo de vigilância e informação vitais à sobrevivência do leitor dentro de uma sociedade em conflito.

\section{Ideologia}

Um anúncio da revista mais vendida no País carrega uma ideologia que o insere numa sociedade de classes. Podemos definir ideologia como "visão de mundo" de uma classe social. A publicidade em exame fala para um "você", um leitor em especial mostrado como livre para a busca de sua ascensão profissional. Na primeira parte do anúncio, defende-se com maior 
veemência a individualidade. 0 jovem executivo aparece como exemplo de sucesso a ser seguido. O lugar a se chegar, o pódio, é o reconhecimento social advindo da posição conquistada via trabalho. Tudo remete, portanto, a uma lógica capitalista, de competição, onde vencem os que se adaptam melhor. E os vencedores lêem VEJA. 0 saber e o poder cedidos pela publicação se ligam a aspectos "práticos" do mundo, não filosóficos, não metafísicos. São de aplicação imediata e vendidos como "receita". É o mundo dos argumentos pragmáticos.

Na primeira parte do anúncio, se apaga o caráter social do trabalho e qualquer idéia de conflito de classe. Encarna-se ainda a dobradinha prêmio/castigo capitalista: riqueza aos vencedores (competentes graças à revista); pobreza, morte, impossibilidade de existência digna aos perdedores. Percebe-se um discurso da classe dominante que reforça a visão de mundo capitalista.

Na segunda parte, a publicidade faz a passagem do que é estritamente individual para 0 coletivo. A revista mostra sua inserção na coletividade, o seu papel social no Brasil. Acreditamos, porém, que a segunda parte do anúncio continua reafirmando o valor das ações individuais dos leitores em detrimento de qualquer sentido de união. Expliquemos. 0 slogan se refere a um "você". O leitor, como já citado, foi representado no seu ato individual de leitura. Para ele, VEJA se coloca como "indispensável" porque cumpre um papel de vigilância sobre o Brasil. A publicação reporta o que vê numa sociedade em ebulição, mas também é parte integrante do próprio Brasil que observa (daí a fusão entre o olho e a bandeira). Cria-se a idéia de um contrato entre revista e leitor que pressupõe, como tarefa da publicação, "cuidar dos assuntos coletivos", colocando-os em pauta, vigiando, pressionando. 0 leitor, que lhe dá sustentação, pode inclusive descansar e ter, depois, as notícias que o interessam na sua caminhada para o sucesso. É VEJA que, do ponto de vista social, se mostra atenta e ativa no lugar do leitor.

O anúncio não busca a mobilização (por mais empregos, por exemplo, ou uma sociedade menos excludente), mas justamente a aceitação de um mundo de extrema competição, de vencedores e perdedores. 0 papel da publicação, num cenário apontado como não passível de mudança, é justamente dar informações aos leitores para que possam tirar o máximo de vantagens na defesa de seus interesses pessoais.

A análise ideológica confirma que a fronteira entre a publicidade, aqui relacionada direta ou indiretamente à comercialização de produtos e serviços, e a propaganda, que inculca valores políticos ou religiosos, é tênue e, ao mesmo tempo, indissociável. 0 anúncio de VEJA se assenta 
sobre a ideologia capitalista, se apóia nela para explicar porque é "indispensável", e reforça essa visão de mundo dominante.

\section{Plano de expressão e relações com o plano de conteúdo}

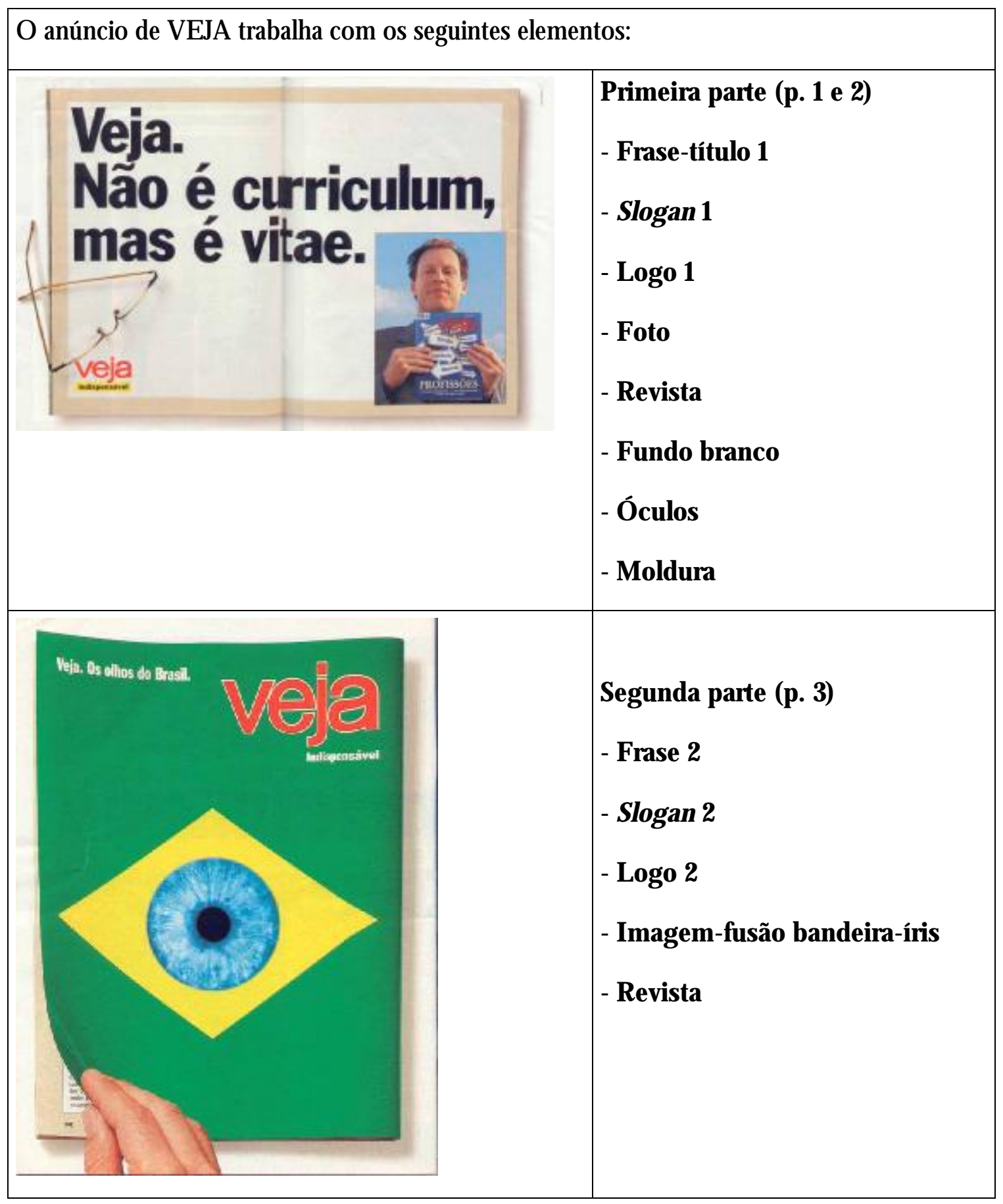


A diagramação teve uma missão importante: simular a própria identidade visual de VEJA. Há diversos elementos que aparecem nas edições semanais e que foram utilizados para permitir o reconhecimento. 0 mais óbvio é uma reprodução do próprio suporte, somente um pouco menor, que possibilita enxergar as páginas e a brochura. Uma moldura bege é mostrada nas três páginas do anúncio. Trata-se de um recurso utilizado na VEJA para destacar o espaço dos analistas (como a última página, reservada aos ensaios de Roberto Pompeu de Toledo), retrospectivas, carta do leitor etc. Na última parte do anúncio, o pedaço da folha com 0 fragmento de texto (de corpo de letra e espaçamento que obedecem ao padrão da revista) tem a numeração "142". 0 total de páginas é comum na publicação.

O tipo de letra utilizado na primeira frase-título (“Veja. Não é curriculum...”) é também 0 mesmo usado nas manchetes de primeira página. Trata-se do Frankfurt G hotic Heavy. Os tipos gráficos manejam relações de seriedade ou leveza, por exemplo, em função da espessura das letras. A frase analisada investe nos sentidos do respeito, da seriedade. As letras em preto acentuam ainda mais a dramaticidade e servem para fazer o máximo contraste com 0 fundo branco.

Para poder hierarquizar os outros elementos não-verbais, é necessário retomar 0 processo de diagramação utilizado. Na publicidade, de uma maneira geral, a composição visual é muito flexível. Não está engessada pela necessidade de se manter um determinado padrão visual. Entretanto, o anúncio estudado, por simular a identidade visual da própria VEJA, permite verificar algumas estratégias de diagramação da revista, que obedecem a quatro leis:

Primeira lei: o valor de uma matéria é proporcional ao espaço dado. Dar mais espaço valoriza. Dar menos espaço desvaloriza. A lei também vale para os elementos constituintes de uma única reportagem. Por exemplo, se há mais fotos do que parte verbal, somos comunicados que as imagens estão sendo mais valorizadas.

Segunda lei: tudo o que estiver na parte de cima da revista tem mais valor do que na parte de baixo. A lei é válida tanto para relação entre textos numa mesma página (ou conjunto de páginas) quanto para elementos de um mesmo texto.

Terceira lei: a máxima valorização espacial de uma revista ou jornal acontece na capa. A primeira página informa o assunto que a revista considera o mais importante da edição. 
Q uarta lei: o início de um texto é o espaço mais valorizado. Essa lei obriga a colocação das principais informações e dos elementos de mais impacto sempre no começo. Por exemplo, uma longa matéria de oito páginas sempre dará a principal foto e abordará o ponto principal do assunto ou na primeira ou no conjunto das duas primeiras páginas.

Sob esse aspecto, a frase-título é o elemento mais valorizado do anúncio, principalmente nas duas páginas em que ocupa quase 50\% do espaço. Em seguida, vem a imagem-fusão da bandeira-íris, que toma praticamente toda a página final. 0 tratamento formal privilegiado comunica que ambas contém os principais conteúdos do anúncio. Um grande título sobre um assunto como o emprego informa um investimento na estratégia emocional, amenizada pela colocação bastante padronizada dos outros elementos.

Nota-se que a maior parte dos elementos (foto, slogan, logotipos) se situam fora do centro das duas partes do anúncio. Temos uma estratégia de apresentação dos elementos "centrífuga" na primeira parte (do centro para fora). Essa montagem, mais a assimetria na construção das páginas duplas, faz com que o olhar tenha que "passear" por todos os espaços para construir os sentidos do anúncio. Na segunda parte, temos uma estratégia contrária, "centrípeda": os elementos, e o próprio olhar do leitor, parecem se dirigir para a pupila do olho-bandeira.

Do ponto de vista das formas, chama a atenção o grande número de retângulos. A revista-simulacro (que aparece duas vezes), as frases, logotipos, slogans, foto e o próprio suporte são retangulares. Para criar contraste, existem as formas arredondadas e irregulares do jovemexecutivo; vemos os óculos, a mão, o pedaço da página (que formam triângulos), e o losango da bandeira. 0 grande elemento que se sobressai do jogo de formas, entretanto, é a íris, com sua forma redonda que possui ainda outro círculo negro no centro, a pupila. É notável ainda que a imagem do jovem executivo foi construída para que cabeça e mãos simulassem, visualmente, "setas" que apontam para a VEJA guia de empregos.

Podemos afirmar que 0 anúncio trabalha com as relações semi-simbólicas ${ }^{7}$ manejadas pela diagramação, em especial a colocação do título, maior elemento da publicidade, na parte

\footnotetext{
${ }^{7}$ A partir de trabalhos de Hjelmslev, se fez distinção entre sistemas simbólicos e sistemas semióticos. Os sistemas simbólicos - como os sinais de trânsito - são linguagens cujos planos de expressão e de conteúdo estão em conformidade total. A cada elemento da expressão corresponde um - e somente um - elemento do conteúdo. Distinguir o plano de expressão (lugar de trabalho de uma ou mais linguagens que vão, no mínimo, carregar os sentidos do plano de conteúdo) e o plano de conteúdo (lugar dos conceitos, ou onde o texto diz o que diz), não traz grandes vantagens para a análise, já que ambos têm a mesma forma. Os sistemas semióticos são linguagens
} 
superior, alinhado à direita, que se relaciona, no plano de conteúdo, ao maior nível de atenção desejado do leitor. Temos ainda, no nível topológico, as relações entre simetria x assimetria, no eidético as formas retangulares $\mathrm{x}$ formas circulares, e no cromático os tons frios (o branco do fundo, 0 bege das laterais) $\mathrm{x}$ tons quentes (como 0 verde e 0 amarelo e 0 azul da bandeira).

De maneira geral, o plano de expressão do anúncio investe em estratégias sensoriais, de contato revista-leitor: do toque, do virar de páginas, da visão de cores, imagens, letras, enfim, da simulação do ato de leitura, que pode ser analisado como um momento de fusão, de máximo contato físico entre publicação e seu público alvo.

\section{Considerações finais}

É possível afirmar que a publicidade de VEJA se dirige a três tipos de enunciatários diferentes. 0 primeiro é formado pelos leitores habituais, que adquirem a revista em banca ou a recebem via assinatura em casa ou no trabalho. 0 segundo é o leitor eventual, que compra apenas quando tem recursos ou algum tipo de interesse específico. Por fim, no terceiro grupo, temos o leitor potencial, aquele que não lê VEJA, mas pode se tornar um comprador habitual. Uma publicidade de VEJA dentro da própria revista mostra que se priorizou o primeiro grupo, ou seja, os leitores habituais. Com as estratégias de castigo (desemprego e insegurança) e recompensa (emprego, sucesso profissional; fluxo contínuo de notícias importantes para se posicionar, poder competir e se precaver num mundo em conflito), cria-se uma tensão maior na relação entre anúncio e leitores habituais. Não está nos limites do trabalho aprofundar o estudo sobre a relação entre a publicidade analisada e a chegada da revista É poca. Entretanto, é notável como o slogan se dirige, com maior carga dramática, ao primeiro grupo. 0 texto diz que não se pode romper uma relação "indispensável" sem que algo ocorra na vida.

Existem outras pistas para aprofundar o perfil do leitor enunciatário. As duas possibilidades de leitura da foto mostradas no nível narrativo, por exemplo, fazem parte de estratégias publicitárias bastante comuns. Permitem que diferentes tipos de leitores - o que quer um bom emprego, o que quer mudar de trabalho, o que está se preparando para entrar no

nas quais não existe conformidade entre os planos. É preciso distinguir e estudar separadamente expressão e conteúdo. As análises semióticas sobre semióticas sincréticas mostraram a importância de um terceiro tipo de sistema, os semi-simbólicos ou poéticos, que se definem não mais pela conformidade entre elementos isolados dos dois planos, mas pela relação entre categorias do plano da expressão e categorias do plano de conteúdo, que criam uma espécie de micro-código. 
mercado - possam projetar suas aspirações sem conflito. $\mathrm{O}$ anúncio tem certa complexidade. A publicidade informa, desse modo, que seu público-alvo tem nível cultural alto em relação à média brasileira e, portanto, competência para "decifrar" os sentidos.

O caráter do anúncio estudado, portanto, é principalmente de reforço dos laços e do contrato existente entre a publicação e o público já cativo. É evidente que a finalidade da estratégia publicitária é fazer o leitor comprar VEJA, base de duas formas diferentes de uma mesma lucratividade. A revista ganha com a comercialização em banca ou assinatura, mas também na venda dos espaços publicitários, calculados em função do número de leitores. Porém, com 0 anúncio analisado, não se pretende vender revista diretamente, mas reforçar e agregar novos valores à marca. Tenta-se fazer o leitor chegar a conclusão do slogan, de que a revista é mesmo "indispensável". Trata-se de uma publicidade interessada em construir e manter relações de fidelidade entre marca e público alvo num momento em que surgiam ofertas de produtos semelhantes.

A construção metadiscursiva do anúncio também é outra estratégia para aumentar a reflexão sobre a marca. Quando o teatro fala do teatro, ou o cinema do cinema, um dos efeitos pretendidos é mostrar potencialidades e limites desses meios de comunicação. Ao figurativizar 0 próprio ato de folhear a revista, ao apresentar a revista diversas vezes, o anúncio constrói um jogo que quer levar o leitor enunciatário a uma reflexão sobre o papel que VEJA desempenha na vida dele.

Para agregar valor à marca "VEJA", a revista escolheu provar-se como "indispensável" de duas maneiras. Temos uma VEJA que se vende como interessada em questões individuais na primeira parte e em coletivas na segunda, ambas, entretanto, como já foi analisado, que falam a um único leitor, a um "você".

O s dois temas escolhidos - o do "vencer na vida" e o da imprensa como quarto poder não deixam dúvidas que a estratégia publicitária, no objetivo de conseguir consumidores mais fiéis, privilegiou mostrar simulacros de relações revista/ leitor de longo prazo, que se mantêm pertinentes com o passar dos anos. A relação do homem com o trabalho, por exemplo, não é imediata. Trata-se de uma das preocupações que o acompanham por quase toda a vida. $\mathrm{Da}$ mesma maneira, não são passageiras, mas constantes, as necessidades de se informar e ter uma imprensa atuante num País em grande transformação. Há, na escolha dos dois temas, uma 
maneira de mostrar que a necessidade de ter VEJA como doadora do saber e do poder vai ser sempre necessária e atual.

A relação entre um doador de saber e poder e um sujeito sem essas competências não é, obviamente, entre iguais. VEJA constrói uma imagem de superioridade. 0 leitor precisa sempre dela, nunca o inverso. Isso ainda acontece em contexto no qual a revista se apresenta com enunciadora "madura", tendo conquistado, pelo aniversário de 30 anos, maior legitimidade para escolher e apresentar os fatos do mundo.

\section{Referências Bibliográficas}

BARRO S, D. L. P. [1988] - Teoria do Discurso - fundamentos semióticos, São Paulo, Atual [1997] - Teoria Semiótica do Texto, 3a edição. São Paulo, Ática.

FIO RIN , J. L. [1996] - As astúcias da Enunciação - as categorias de pessoa, espaço e tempo . São Paulo, Ática. [1997] - Linguagem e Ideologia, 5a edição. São Paulo, Ática. , [1997a] - Elementos de Análise do Discurso, São Paulo, Editora da Universidade de São Paulo.

$\overline{\mathrm{F}} \mathrm{L} \mathrm{O} \overline{\mathrm{H}} \mathrm{H}, \mathrm{J} . \mathrm{-}$ - $\mathrm{M}$. [1985] - Petites mythologies de l'oeil e de l'espirit - Pour une sémiotique plastique, ParisAmsterdam, Hadès-Benjamins.

PERELMAN, C. \& TYTECA, L. O. [1999] - Tratado da Argumentação - A Nova Retónica, São Paulo. Martins Fontes.

Artigos:

CIVITA, Roberto. "A dura tarefa de transformar o importante em interessante". VEJA 1569, edição especial de 30 anos. 